\title{
Identification of dermatophytes isolated from ringworm lesions of camels.
}

\author{
Enany, M. E., khafagy, A. R., Madiha S. Ibrahim ${ }^{1}$, Marwa M. Azab and \\ ${ }^{2}$ Dalia T. Hamad'.
}

Department of Microbiology, Faculty of Veterinary Medicine, Suez Canal

University, Ismailia Egypt. And ${ }^{2}$ Damnhour University, El Bostan, Egypt.

\section{ABSTRACT:}

Objective: phenotypic and genotypic identification of dermatophytes isolated from skin lesions of camels.

In this study 70 specimens of hair and skin scrapings were taken from camels with skin lesions from El - Beheira Governorate ( Junbway / Kom Hamada / El - Dalngat), El- Giza Governorate (Briqash ) and El - Sharkia Governorate ( Belbeis ) for identification of common dermatophytes of camels using conventional techniques macromorphology, micromorphology and physiological test and compared with molecular method (polemerase chain reaction) using the short oligonucleotide (GACA)4 as a primer for identification of the tested dermatophyte isolates. ( GACA) 4 based PCR identified the tested isolates from camel skin lesions to the species level in full agreement with the culture-based method.

Keywords: dermatophytosis -camel -identification.

\section{INTRODUCTION}

The dermatophytes are a group of closely related fungi that utilize keratin for growth. They tend to be confined to the outer stratum corneum of the skin, claws, and fur of animals. The classical lesions are circular, and known as "ringworm". (Weitzman and Summerbell, 1995). This closely-related group of organisms can be categorized into one of three genera: Trichophyton, Microsporum, and Epidermophyton. As a number of fungi, dermatophytes may exhibit two phases in their life cycle: the anamorph state (imperfect or asexual phase), which isolated in the laboratory; and the teleomorph state (perfect or sexual phase). Not all of the teleomorphs for dermatophyte species have been identified (Mukherjee et al, 2011). Anamorphic states (genera Epidermophyton, Microsporum and Trichophyton) belong to the Hyphomycetes and phylum Deuteromycota and teleomorphic states (the majority of geophilic and zoophilic species of Microsporum and Trichophyton) are classified in the teleomorphic genus 
Arthroderma, order Onygenales, phylum Ascomycota, and are usually found in their anamorphic state (Molina, 2011).

The dermatophytes have been divided into three ecological groups: geophiles, zoophiles and anthropophiles. Geophiles are primarily soil-inhabiting and only rarely encountered as agents of ringworm, with the exception of $M$. gypseum. Zoophiles are essentially animal pathogens, although they may cause infection in humans. Anthropophiles are restricted to man, very rarely infecting animals (Simpanya, 2000).

Dermatophytes are cited among the most frequent causes of dermatological problems in domestic animals. However, only a few species belonging to the genera Microsporum and Trichophyton are usually the cause of dermatophytosis in these animals. In very few cases, anthropophilic species have been mentioned as a cause of dermatophytosis in animals. However some geophilic dermatophytes are normally the cause of a relatively low number of cases of ringworm. Animals serve as reservoirs of the zoophilic dermatophytes, and their infections have considerable zoonotic importance (Cabañes, 2000).

A wide variety of dermatophytes have been isolated from animals, but a few zoophilic species are responsible for the majority of the cases, Microsporum canis, Trichophyton mentagrophytes,
Trichophyton equinum and Trichophyton verrucosum, as also the geophilic species Microsporum gypseum (Chermette et al, 2008). The zoophilic dermatophyte $T$. verrucosum is associated principally with cattle and camel ringworm but it has been reported to infect a wide range of animal's hosts with man. In animals, the lesions start with thickening of skin, alopecia and scaliness. They may involve small circular areas or become confluent in extensive areas (Shathele and Fadlelmula, 2010).

The young camels up to three years of age were most affected by ringworm (dermatophytosis), while older camels were rarely affected (Fadlelmula et al, 1994 and Agab and Abbas, 1999). Lesions tend to be non-pruritic and alopecic, with thick crusts (Cebra, 2011), similar to those seen in cattle on the head, the neck and shoulders, with a possible extension to the flanks and legs, leading sometimes to pyoderma and emaciation (Chermette et al, 2008).

Conventional laboratory identification of dermatophytes still consists primarily of micro- and macromorphological examination of primary isolates, supplemented with physiological tests. The results of direct specimen microscopy are also still important (Graser et al, 2008).

Mycological culture remains the gold standard for the diagnosis of animal dermatophytosis and the only method for the phenotypic 
identification of dermatophyte species. There are several media available for isolation of dermatophytes but Sabouraud dextrose agar supplemented with cycloheximide to avoid growth of contaminants, and antibacterial drugs like chloramphenicol or penicillin-gentamicin, is traditionally recommended for primary cultures (Chermette et al, 2008).

Many molecular approaches have been applied for identification of different dermatophyte species and strains. Faggi et al (2001) and Shehata et al (2008) used a onestep PCR-based approach employing the simple repetitive oligonucleotide (GACA) 4 as a single primer for identification of species of dermatophytes. Their data showed that this simple primer was able to amplify all the studied dermatophytes with production of species-specific PCR profiles.

So the aims of this study:

1- Isolation of dermatophytes from camel cases.

2- Identification of dermatophytes by conventional methods.

(Phenotypic identification).

3- Molecular identification of dermatophytes

(Genotypic identification).

\section{Material and methods}

In the present study 70 specimens of hair and skin scrapings were taken from camels with skin lesions suspected to be dermatophytes infection from El -Beheira Governorate (Junbway /Kom Hamada/ El -Dalngat ), El- Giza Governorate (Birqash) and ElSharkia Governorate (Belbeis) and were subjected to mycological examination .

Table (1): Age and number of examined camels from each Governorate.

\begin{tabular}{|l|c|c|c|}
\hline $\begin{array}{c}\text { Age (years) } \\
\text { Localities }\end{array}$ & $\boldsymbol{< 2}$ & $\mathbf{> 2}$ & $\begin{array}{c}\text { Number of collected } \\
\text { specimens }\end{array}$ \\
\hline EI - Beheira & 26 & 11 & 37 \\
\hline El- Giza & 12 & 5 & 17 \\
\hline El - Sharkia & 7 & 9 & 16 \\
\hline Total number & 45 & 25 & 70 \\
\hline
\end{tabular}

\section{Collection of samples}

The samples should were collected in a sufficient amount by scrapings of the active edge of the affected skin from lesions suspected to be ringworm by sterile scalpel, after cleaning the lesions by a gauze moisted in $70 \%$ ethyl alcohol. Hair near the advancing border of the lesion was epilated from its root by forceps. Samples (scales and hair) were collected in disposable sterile petridishes and transferred to laboratory with its full data for mycological examination. 
Direct microscopic examination

Small portion of the collected samples (hair and skin scrapings) were placed on a microscopic slide with a drop of $20 \%$ potassium hydroxide and covered with a cover slip additional drops of $\mathrm{KOH}$ solution were added from the side of the cover if needed that spread under the cover by capillarity to replace air bubbles, then the slide was heated gently over Bunsen flame(not boil , only three to four passages on the flame), the slide was left for 20-30 min then examined under low and high power magnification for the presence of fungal elements as long branching septated hyphae or arthrospores.

A prolonged clearing time and an accurate observation are required due to thick crusty lesions.

\section{Culture}

After direct microscopic examination, irrespective of demonstration of fungal elements, the specimens were cultivated on :-

1. Cultivation on Sabouraud's dextrose agar (SDA) with chloramphenicol (50 $\mathrm{mg} / \mathrm{L})$ and cycloheximide $\quad(500 \quad \mathrm{mg} /)$ (MAST) (Laron, 1976).

The specimens were cut out into small pieces by sterilized needle and scalpel, a light inoculum of each hairs and skin scrapings specimen was picked up with sterile forceps and scattered at centre location on the surface of the medium and gently pressed down into the agar. The cultures were labeled with the specimen number and date of inoculation. Then incubated at $25-30{ }^{\circ} \mathrm{C}$ for three weeks, it was preferable not to discard the negative culture before one month.

2. Cultivation on dermatophyte test medium (DTM) (HIMIDIA Indian)(Taplin et al., 1969)

Subculturing was done on DTM then incubated at room temperature for 10 to 14 days. As dermatophyte test medium (DTM) a special media has been formulated for growing and identification of dermatophytes. Without having to look at the colony one can identify the dermatophyte by a simple color test. If the fungus is a dermatophyte, the medium will turn bright red. If the fungus is not a dermatophyte, no color change will be noted. If kept beyond 14 days, false positive can result even with non-dermatophytes.

The mycological identification was based on macroscopic and microscopic examination of the culture isolates.

\section{a-Macromorphology}

The colonies were examined from all aspects for rate of growth whether slow or rapid, topography (flat, heaped, regularly or irregularly folded), texture (yeastlike, glabrous, powdery, granular, velvety or cottony), surface pigmentation and reverse pigmentation.

b-Micromorphology

It was done by taking a small part from the colony by a sterile needle 
into a glass slide and a drop of cotton blue was added, with needle tease the specimen and remove any hard parts or remaining of the agar then cover with a cover slide , LPCB was added if needed. The slide was examined by low and high power to demonstrate the presence of hyphae and its modification, macroconidia, microconidia, chlamydospores and other fungal structure.

\section{Physiological tests}

Dermatophyte species were further confirmed based on urease test, hair perforation test and rice grain test.

Genotypic identification of dermatophytes

DNA extraction (Liu et al., 2010)

DNA extracted from isolated dermatophytes species using Biospin fungus genomic DNA extraction kit. (Bioer Technology Co., Ltd., Hangzhou, P.R. China) At first, the sample was lysed in LE buffer, and then DNA in the sample was liberated. After adding DA buffer and centrifuging, the impurity was discarded, released DNA was bound exclusively and specifically to the Biospin membrane in presence of a $E$ Binding buffer under appropriate salt iron and $\mathrm{PH}$ conditions. Denaturated protein and other contaminants were removed by several washing procedures. The DNA was then eluted from the membrane with the Elution buffer.The extraction occurred according to manufactures protocol.
PCR method using the (GACA) 4 primer.

Short oligonucleotide (GACA $)_{4}$ (Operon Biotechnologies, USA) was used as a primer for identification of the tested dermatophyte isolates as described by Shehata et al (2008). Amplification reactions were carried out with volumes of $50 \mu \mathrm{l}$ containing reaction buffer $[50 \mathrm{mM}$ $\mathrm{KCl}, 10 \mathrm{mM}$ Tris- $\mathrm{HCl}$ (pH 9.0), 2.5 $\mathrm{mM} \quad \mathrm{MgCl}_{2}$, deoxynucleoside triphosphate mix $(0.2 \mathrm{mM}$ each of dATP, dCTP, dGTP, and dTTP), $160 \mathrm{ng}$ of the (GACA) 4 primer (Operon Biotechnologies), $2.5 \mathrm{U}$ of Taq polymerase ( Sigma, USA). and approximately $25 \mathrm{ng}$ of template DNA, made up to a total volume 50 $\mu 1$ with pure, sterile double-distilled water]. PCR was carried out for 39 cycles of denaturation at $93^{\circ} \mathrm{C}$ for 1 min, annealing at $50^{\circ} \mathrm{C}$ for $1 \mathrm{~min}$, and extension at $72^{\circ} \mathrm{C}$ for $1 \mathrm{~min}$, followed by a final extension step at $72^{\circ} \mathrm{C}$ for $7 \mathrm{~min}$.

\section{Agarose gel electrophoresis}

A volume of $10 \mu \mathrm{l}$ PCR products were mixed with $3 \mu \mathrm{l} 6 \mathrm{x}$ loading buffer. The samples were then run on $1 \%$ agarose gel with $0.5 \mu \mathrm{g} / \mathrm{ml}$ ethidium bromide. The gel was run in an electrophoresis gel tank at $35 \mathrm{v}$ for 2.5 hours in $0.5 \mathrm{x}$ Tris-BorateEDTA buffer $(45 \mathrm{mM}$ Tris-borate, PH 8.3, $1 \mathrm{mM}$ EDTA). Sizes of PCR products were determined by comparing them to a 3000-bp DNA ladder. The DNA was visualized by UV light and photographed using a gel Documentation System. 


\section{Results and discussion}

\section{Clinical findings}

Camel dermatophytosis may involve small circular area which mostly appeared on the belly, shoulder and head or become confluent in extensive areas which affect all the body from tip of hump and extend downward with possible extension to legs.

As shown in Fig. 1, 2, 3\&4. The lesions tend to be non-pruritic and alopecic with grey white, thick and heavy encrustation difficult to pull out of the skin, it most often appeared as several annular or irregular areas of alopecia distributed on various parts of the body specially flank, shoulder, fig. 5 .

Young camels' between1-2 years old or less were more commonly affected than mature healthy camels. Signs of emaciation and fatigue appeared in most affected animals.
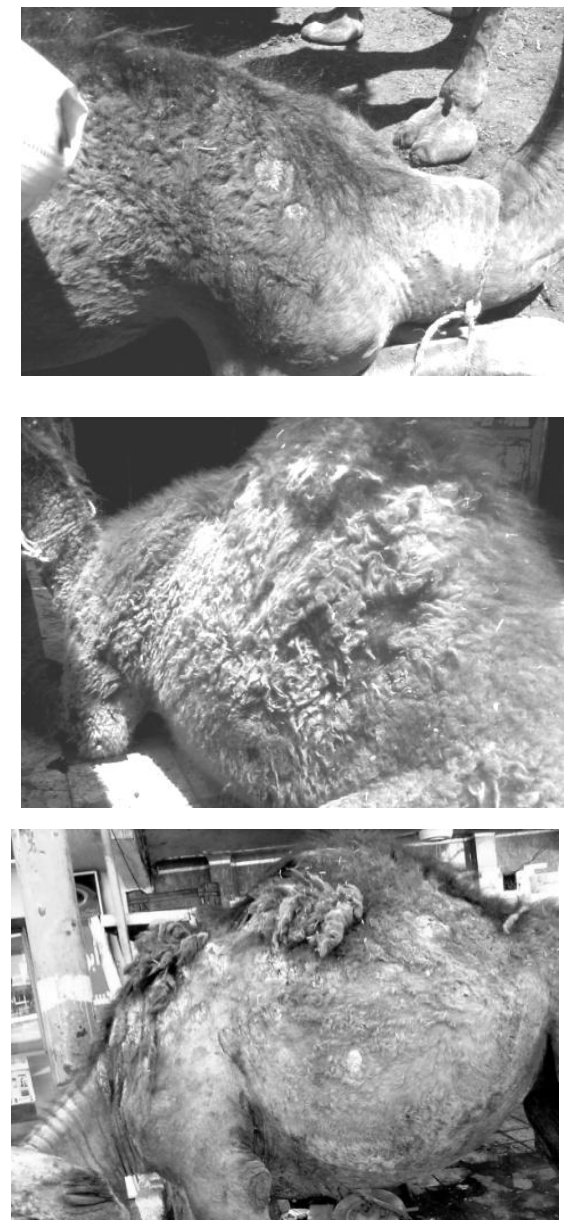

Fig.1: A young camel calf has Crusty and hairless lesions on the shoulder.

Fig. 2: A young camel calf have circumscribed, crusty and hairless lesions on the belly due to dermatophytes

Fig.3: Affected camel showed white hairless patches on different parts of the body. The lesions typically consisted of an area of alopecia. 

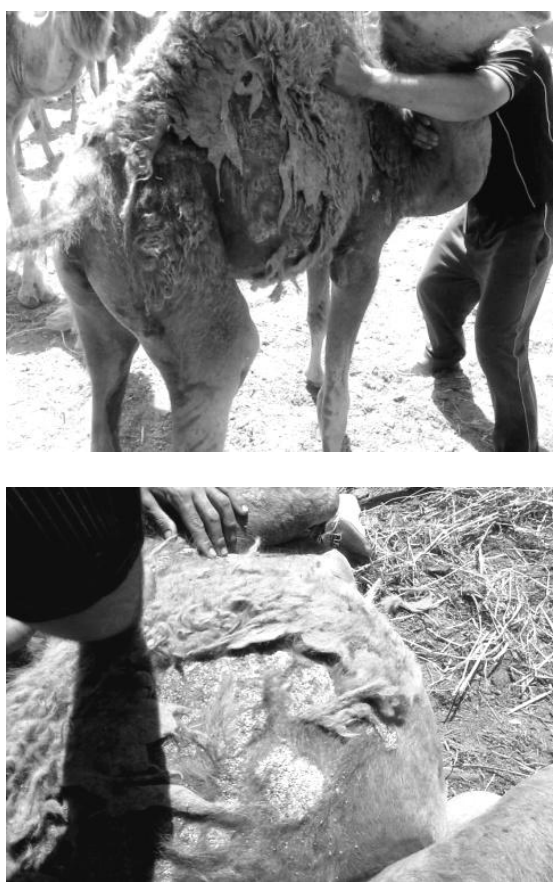

Direct microscopic examination

Direct microscopic examination using $\mathrm{KOH} 20 \%$ did not allow precise identification as affected camels have thick crusts and visualization of fungal elements is difficult by using $\mathrm{KOH}$ alone so irrespective of positive or negative $\mathrm{KOH} 2 \mathrm{O} \%$ culturing on suitable growth media is necessary this result was in agreement with Robert and Pihet (2008).

\section{Culture}

Mycological examination of hair and skin scrapings collected from 70 camel cases showed skin lesions revealed that all specimens (25) collected from camels aged over two years were negative for dermatophytes while specimens (45) from camels aged under two years 15 were negative for dermatophytes and 30 were positive
Fig. 4: Affected camel showed heavy incrustation on different parts of the body and progressed down to belly and legs.

Fig. 5: A prominent grayish white accumulation of scales on the belly difficult to pull out of the skin (thick and heavy encrustation) due to severe dermatophytosis.

for dermatophytes so the younger were more susceptible for dermatophytosis than old one.

It mentioned that ringworm (dermatophytosis) usually occur in young camels, while old camels were rarely affected. These results were in agreement with those obtained by many outhers Khamiev (1981), McGrane and Higgins (1985), Abdurahman and Bornstein (1991) , Mahmoud (1993), Fadlelmula et al (1994), Agab and Abbas (1999), Abbas and Omer (2005), Chermette et al (2008) and Raziq et al (2010).

The obtained dermatophytes isolates were identified by macromorphology and micrmorphology into $22(73.33 \%)$ Trichophyton mentagrophytes, $5(16.66 \%)$ 
verrucosum, 3(10\%) mixed between

T.verrucosum .

T.mentagrophytes

and

Table (2): Culturing of hair and skin scrapings taken from camels with skin lesions.

\begin{tabular}{|c|c|c|c|}
\hline Age of camels & $\begin{array}{c}\text { Number of } \\
\text { collected } \\
\text { specimens }\end{array}$ & $\begin{array}{c}\text { Positive } \\
\text { specimens for } \\
\text { culturing }\end{array}$ & $\boldsymbol{\%}$ \\
\hline$<2$ & 45 & 30 & 42.85 \\
\hline$>\mathbf{2}$ & 25 & - & 0 \\
\hline Total & 70 & 30 & 42.85 \\
\hline
\end{tabular}

Table (3) Identification of 30 dermatophyte isolates obtained from 70 camels with skin lesions.

\begin{tabular}{|c|c|c|}
\hline Dermatophyte species & No of isolate & \% to+ve culuture \\
\hline T.mentagrophytes & 22 & $73.33 \%$ \\
\hline T.verrucosum & 5 & $16.66 \%$ \\
\hline $\begin{array}{c}\text { Mixed (T.mentagrophyte } \\
\text { andT.verrucosum) }\end{array}$ & 3 & $10 \%$ \\
\hline Total no of isolates & 30 & $100 \%$ \\
\hline
\end{tabular}

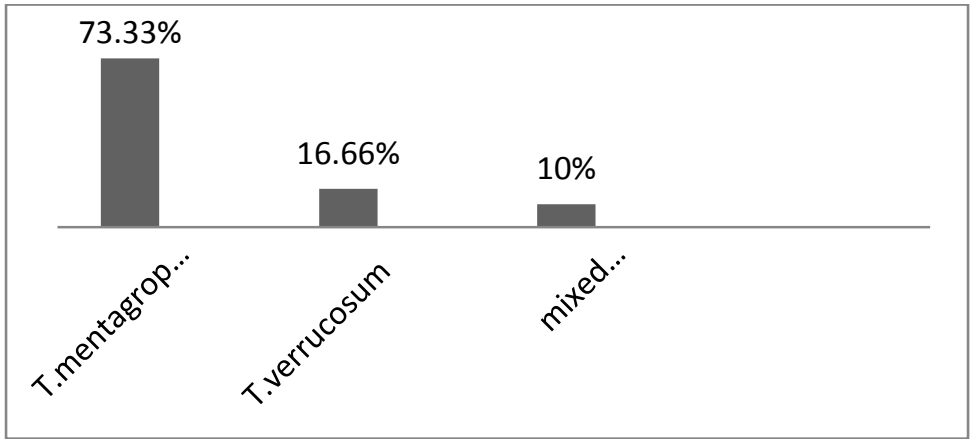

Fig (1): Distribution by species of 30 dermatophyte isolates obtained from 70 camels with skin lesions

It mentioned that T.mentagrophytes appeared to be the main cause of ringworm in young camels this result disagree with Mahmoud (1993) , Agab and Abbas (1999) and Chermette et al (2008) who stated that $T$. verrucosum appeared to be the main cause of ringworm in small camels.

Identification of dermatophytes by use of (GACA $)_{4}$ primer-based PCR. 
All of the studied strains were amplified with this simple, repetitive primer, and the numbers of the resulting PCR bands ranged from 2-5. Three profiles for Trichophyton mentagrophytes have been detected as T.mentagrophytes is known to be a species complex composed of several species or variants, which occur in both human and animals in which the number of the resulting PCR bands ranged from 2-5. The first profile (lane 1-6) consisted of three bands ranging from 300- $1000 \mathrm{bp}$ with two strong bands of $300 \& 800 \mathrm{bp}$, the second profile (lane 7-9) consisted of five bands ranging from 200-950 bp with three strong bands and two faint bands and the third profile (lane 10-11) consisted of five bands with one strong band of 600 bp. Trichophyton verrucosum (lane 12-14) consisted of two faint bands at $300 \& 800 \mathrm{bp}$ as shown in photo(6).

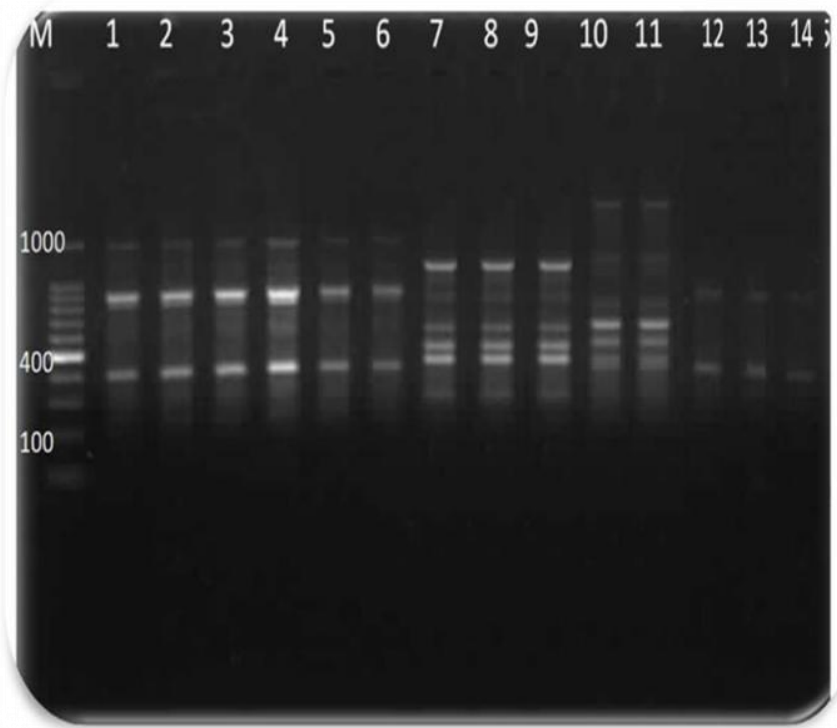

\section{Photo(6)):Agarose gel electrophoresis for PCR using (GACA)4}

$\mathrm{M}$, molecular weight marker.

Lanes (1-6) first profile of T.mentagrophytes

Lanes (7-9) second profile of T.mentagrophytes.

Lanes (10\&11) third profile of T. mentagrophytes

Lanes (12-14) T.verrucosum

\section{Conclusion}

- Camel

dermatophytosis

(ringworm) mainly affects young camels under two years while old rarely affected.
- T.mentagrophytes responsible for the majority of infection cases beside T.verrucosum.

- Culture has the great advantage of detecting dermatophytes by the 
morphological characters on media with special morphology for each species but time consuming.

- PCR based on (GACA)4 has been shown to be a useful tool in molecular identification of dermatophytes which successfully identified the tested isolates to the species level in full agreement with both the culture-based method.

\section{References}

Abbas B. and Omer OH. (2005): Review of infectious diseases of the camel. Veterinary Bulletin; 75(8): 1-16.

Aburahman O.S. and Bornstein S. (1991): Diseases of camels in Somalia and prospects for better health. Nomadic peoples, number 29, Commission on nomadic peoples.

Agab H. and Abbas B. (1999): Epidemiological studies on camel diseases in eastern Sudan. World Animal review; 92 (1): 42 - 51.

Cabañes F. J. (2000): Dermatophytes in domestic animals. In Biology of dermatophytes and other keratinophilic fungi chapter: 13 Revista Iberoamericana de Micología, Bilbao.

Cebra C.K (2011): Camelid dermatology. $63^{\text {rd }}$ CVMA Convention-scientific presentations. Chermette R., Ferreiro L. and Guillot J. (2008): Dermatophytoses in Animals. Mycopathologia; 166:385-405.

Fadlelmula A., Agab H., Horgne J.M., Abbas B. and Abdalla A.E.
(1994): First isolation of Trichophyton verrucosum as the aetiology of ringworm in the Sudanese camels (Camelus dromedarius). Rev Elev Med Vet Pays Trop; 47(2):184-187.

Faggi E., Pini G., Campisi E., Bertellini C., Difonzo E. and Mancianti F. (2001): Application of PCR to Distinguish Common Species of Dermatophytes. J Clin Microbiol. 39(9): 3382-3385.

Graser Y., Scott J. and Summerbell R. (2008): The New Species Concept in Dermatophytes a Polyphasic Approach Mycopathologia.166(5-6):239-256.

Khamiev S.K.H. (1981): Camel ringworm. Buylleten vs esoyuzuogo institute.Eksperimental Noi Vertrinarig, 42:14-17.

Liu A., Bao F., Li M., Shi M., Saising J. and Shen P. (2010): Biodiversity of cultivable fungi in hair samples from tree shrews. African Journal of Microbiology ; 4(24): 2704-2707.

\section{Mahmoud A.L.}

(1993):

Dermatophytes and other associated fungi isolated from ringworm leions of camels. Folia Microbiol (Praha); 38(6):505-508.

McGrane J.J. and Higgins A.J. (1985): Infectious diseases of the camel: Viruses, bacteria and fungi British Veterinary Journal 141:529547.

Molina D.A. (2011): Clinical, diagnostic and therapeutic aspects of dermatophytosis. Enferm Infecc Microbiol Clin; 29 ( 3):33-39. 
Mukherjee P.K., Isham N. and Ghannoum

Molecular M.A (2011): Diagnostics

Dermatology

Dermatopathology .Current Clinical Pathology, 311-337. Infectious Diseases of the Skin I Dermatophytosis/ Onychomycosis.

Raziq A., Verdier K. and Younas M.(2010): Ethnoveterinary treatments by dromedary camel herders in the Suleiman Mountainous Region in Pakistan. Journal of Ethnobiology and Ethnomedicine; 6:16.

Robert R. and Pihet M.(2008):Conventional methods for the diagnosis of dermatophytosis.Mycopathologia.1 66(5-6):295-306.

Shathele M.S and Fadlelmula A. (2010): In vitro effectiveness of some antifungal drugs in treatment of Trichophyton verrucosum, dermatophytic fungi. Asian journal of animal and veterinary advances; 5 (3):180-192.

Shehata A.S., Mukherjee P.K., Aboulatta H.N., El Akhras A.I., Abbadi S.H. and Ghannoum M.A. (2008): Single-Step PCR Using (GACA)4 Primer: Utility for Rapid Identification of Dermatophyte Species and Strains.J. Clin. Microbiol.46 ( 8): 2641-2645.

Simpanya M. F. (2000): Dermatophytes: Their taxonomy,ecology and pathogenicity.

Revista Iberoamericana de Micología, Bilbao,1-12.

Weitzman I. and Summerbell R.C. (1995): The dermatophytes. Clin. Microbiol. Rev. 8: 240-259. 


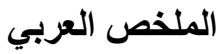

أجريت هذه الدراسة للتعرف علي أنواع المسببات الفطرية التي تسبب القراع في الجمال و لاجر اء ألاء

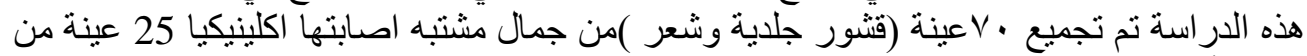

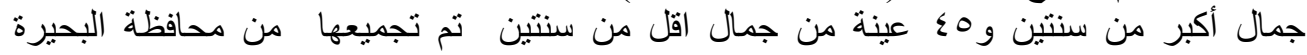

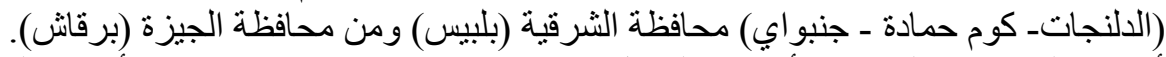

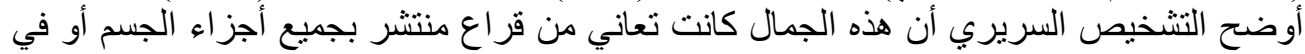

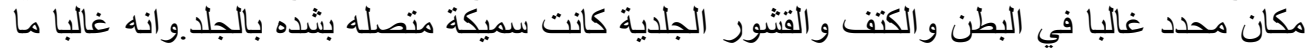

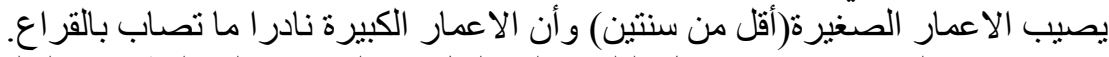

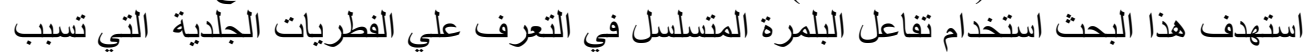

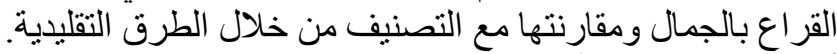
أولا الطرق التقليدية:- الجزء الاول للفحص الميكروسكوبي المباشرباستخدام البوتاسيوم هيدروكسيد

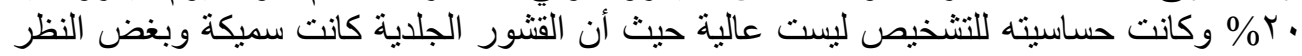

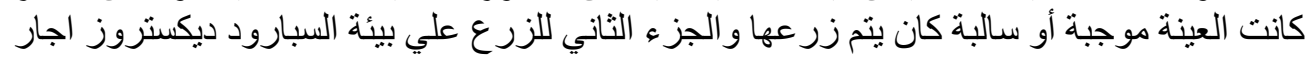

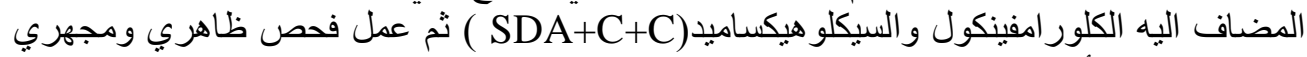

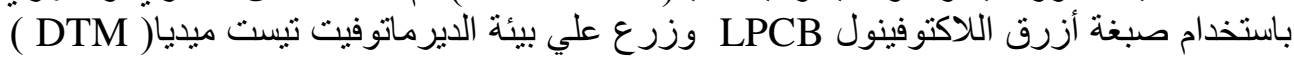

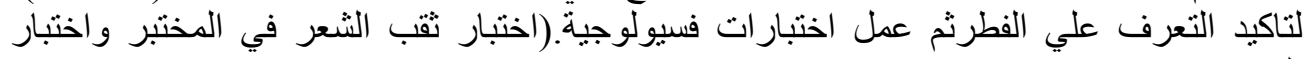

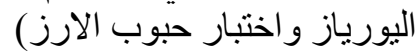

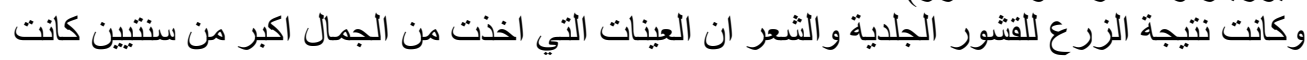

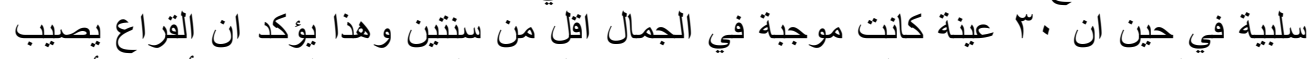

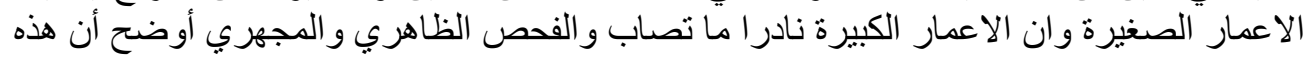

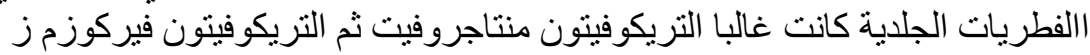

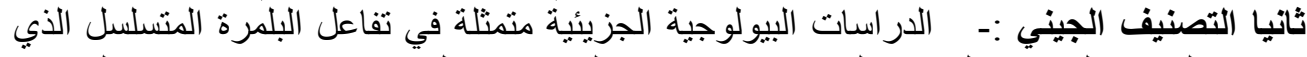

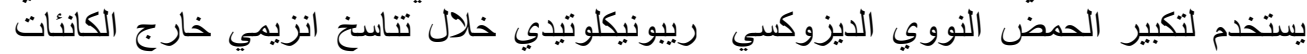

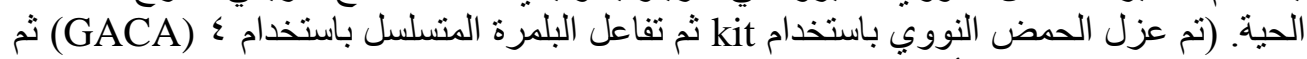
electrophoresis

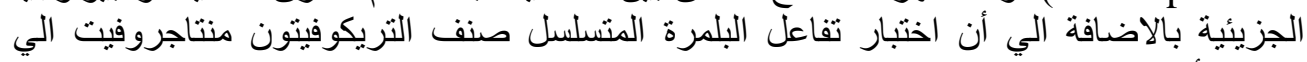
مستوي أكثر تقدما. وفي الخاتمة تنيين أن استخدام البيئات للزر عل بجانب الفحص المجهري بعد طريقة سهلة ولكنها بطيئة

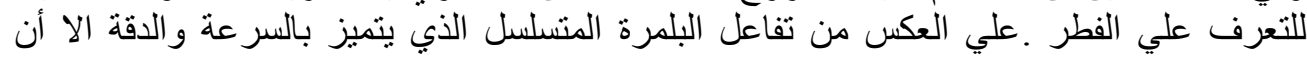

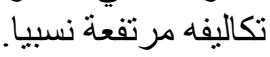

